\title{
Lupus and Pregnancy: Complex Yet Manageable
}

\author{
Josephine Patricia Dhar, MD and Robert J. Sokol, MD
}

\begin{abstract}
Systemic lupus erythematosus is a chronic multi-system autoimmune disease that occurs predominantly in women of childbearing age. The risk of complications and adverse fetal outcomes in pregnant women with lupus is high. Moreover, pregnancy can cause flares of lupus disease activity necessitating maternal immunosuppressive intervention. Interestingly, many potential complications of pregnancy present as symptoms of lupus making diagnosis and treatment a challenge.Advancing technology and better understanding of the maternal-fetal dyad in lupus have improved outcomes in lupus pregnancies over the last 40 years. This article will briefly review the important issues in pregnancies complicated by lupus and provide a general guideline to physicians for monitoring and treatment.
\end{abstract}

Keywords: Fetal outcomes; Lupus; Maternal outcomes; Pregnancy; Systemic lupus erythematosus

\section{$\mathrm{S}$} multi-system autoimmune disease that occurs predominantly in women of childbearing age. ${ }^{1-4}$ Hence, pregnancy is an important clinical setting for disease management in this group of patients. Complications of pregnancy, particularly preeclampsia, can be difficult to distinguish from symptoms of lupus making diagnosis and treatment challenging. Lupus can be detrimental to the pregnancy and may cause adverse fetal outcomes. Conversely, pregnancy can cause flares of lupus disease activity often times necessitating maternal immunosuppressive intervention. Advances in the understanding of the pregnancy-lupus interaction has resulted in better methods of monitoring and treating this clinical situation. As a result, maternal and fetal outcomes have improved over the last few decades. This article will briefly review the important issues related to pregnancies complicated by lupus and will provide a general guideline to physicians for monitoring and treating women with lupus during their pregnancies.

\section{Systemic Lupus Erythematosus}

Lupus is a serious disease with significant morbidity and mortality. Approximately $90 \%$ of patients with lupus are women. More severe disease occurs in males, African Americans and Asians resulting in increased morbidity and higher mortality rates in these groups. ${ }^{5-8}$ Patients with lupus experience frequent hospitalizations and usually require multidisciplinary care. In addition, end-organ damage resulting from disease and treatment-related side effects can cause considerable disability. It is not surprising that women given the diagnosis of lupus are often concerned about becoming pregnant and may be apprehensive about their ability to fulfill their maternal responsibilities.

Lupus is characterized by autoantibody production and a dysfunctional immune system resulting in organ inflammation and consequent damage. Because lupus can present with a varied spectrum of signs and symptoms which are often nonspecific, the diagnosis can be difficult to make. Lupus is a definitive diagnosis when at least 4 of the 11 of the American College of Rheumatology's criteria for lupus are fulfilled. ${ }^{9}$ A positive antinuclear antibody test is the characteristic laboratory test used to help diagnose lupus. However, this test, by itself, has poor predictive power and is, thus, not useful as a screening test for lupus. It only has significance if the index of suspicion is high, based on the clinical history and laboratory abnormalities. For this reason, using this test to screen for early lupus is not reasonable. Lupus flares are characterized by specific laboratory abnormalities including elevated anti-double-stranded DNA antibody titers and low complement $\left(\mathrm{C} 3, \mathrm{C} 4, \mathrm{CH}_{50}\right)$ levels. 
Assessment of disease activity at each visit should be based on both clinical and laboratory data.

Almost any organ can be involved in lupus, resulting in a wide variety of clinical manifestations and symptomatology. Patients with lupus can have constitutional symptoms of fatigue, weight loss and fevers. Musculoskeletal manifestations include polyarthritis and inflammatory myositis. Mucocutaneous symptoms such as recurrent oral/nasal ulcerations, alopecia, Raynaud's phenomenon, photosensitive skin rash, discoid lupus, malar rash and subacute cutaneous lupus rash occur frequently. Common cardiopulmonary manifestations of lupus include pleural or pericardial effusions and pulmonary fibrosis. Less common cardiopulmonary manifestations include myocarditis, Libman Sacks endocarditis and coronary arteritis. Hematological manifestations of lupus include Coombs' positive hemolytic anemia, leukopenia, lymphopenia and thrombocytopenia. Major organ involvement of the renal system (lupus nephritis) or central nervous systems (stroke, seizures, coma) worsens the overall prognosis. Thrombophilia can result from antiphospholipid antibodies (i.e., anticardiolipin antibodies, lupus anticoagulant or false-positive rapid plasma reagin) which promote intravascular thrombosis of arteries and veins. Organ involvement can be varied and nonspecific resulting in a broad spectrum of disease. This can make diagnosis difficult and result in delayed treatment.

The intensity of immunosuppressive treatment should be based on disease severity and type of organ involvement. Treatment options have previously been summarized by O'Neill and Schrieber ${ }^{10}$ and will be briefly reviewed here. Hydroxychloroquine (Plaquenil) is used for mild cutaneous and musculoskeletal involvement. Corticosteroids are used in low doses for mild disease and in moderate to high doses for more severe disease. Cytotoxic therapy with mycophenolate mofetil (CellCept), cyclophosphamide (Cytoxan) or azathioprine (Imuran) is indicated for moderate to severe disease, particularly for lupus nephritis and cerebritis. Promising new biological therapies are evolving utilizing targeted lymphocyte B-cell depletion and lymphocyte B-cell immune modulation. One of the most recent biological drugs being used to treat lupus is rituximab (Rituxin), which is a chimeric mouse/human antibody to $\mathrm{CD}_{20}$, a B-cell specific surface marker. ${ }^{10}$ Effective immunosuppressive therapy is essential to control active lupus. However, treatment during pregnancy is largely limited by the risks to the fetus of being exposed in utero to these drugs.

\section{Normal Pregnancy and Complications}

Manifestations of a normal pregnancy can sometimes be confused with lupus disease activity. Thus, it is important to understand the changes that happen during a normal pregnancy. Because of normal physiological changes, the limits for defining abnormalities and the thresholds perceived as danger signals change during pregnancy. In a normal pregnancy, plasma volume, cardiac output and sodium load increase, and systemic vascular resistance falls with a resultant drop in blood pressure of $10 \mathrm{mmHg} .{ }^{11} \mathrm{In}$ addition, the glomerular filtration rate increases with creatinine clearance usually at a rate $>100 \mathrm{ml} / \mathrm{min}$. Consequently, a blood urea nitrogen of $>13 \mathrm{mg} / \mathrm{dl}$ and a serum creatinine of $>0.8 \mathrm{mg} / \mathrm{dl}$ are considered to reflect renal impairment in pregnancy. Urinary excretion of protein increases during pregnancy to 150 to $184 \mathrm{mg} / 24$ hours. ${ }^{11}$ Thus, mild elevations of serum creatinine and blood pressure are taken more seriously during pregnancy, but daily proteinuria should exceed approximately $200 \mathrm{mg}$ to be considered significant. An excess of pregnancy-related progesterone can result in hyperventilation and dyspnea along with smooth muscle relaxation of the renal outflow tract predisposing the expectant mother to urinary tract infections. ${ }^{11}$ The dyspnea related to pregnancy can be difficult to distinguish from pathologic cardiopulmonary conditions. Although the white blood cell count increases, the differential remains normal. To allow tolerance of the fetus, pregnancy produces an environment of immune suppression with depressed immune function of natural killer cells, phagocytic cells and cell mediated cytotoxicity. Antibody dependent cellular cytotoxicity function, however, remains normal. ${ }^{11}$ Complement levels rise due to an estrogen-induced increase in hepatic synthesis. ${ }^{12,13}$ Incidental thrombocytopenia occurs in $8 \%$ of women during pregnancy and can be difficult to distinguish from low platelets related to a lupus flare or a pregnancy complication. ${ }^{14}$ Thrombocytopenia during pregnancy is generally mild and does not cause bleeding problems. Conversely, thrombophilia can be a major problem during pregnancy. Pregnancy is a state of thrombophilia, and thromboembolism is increased 5-fold due to changes in levels of clotting factors, as well as mechanical factors. ${ }^{15}$ During pregnancy, changes in coagulation factors include pregnancy-induced protein $\mathrm{S}$ deficiency and increased fibrinogen, factor II, factor VII and thrombin. Mechanical factors contributing to thrombosis during pregnancy include venous stasis, uterine venous compression and bed rest. ${ }^{15}$ Other clinical manifestations of a normal pregnancy include arthralgia, back pain, malar erythema, palmar erythema, edema and heartburn. Differentiating pathologic signs and symptoms of lupus from pregnancy-related effects can be challenging for the physician and is extremely important in determining proper treatment.

Complications of maternal hypertension, as well as fetal loss and growth restriction, are important issues for expectant mothers with lupus. For this reason, it is important to be familiar with the terminology for both categories. Maternal hypertensive complications can be confused with lupus. Table 1 summarizes the terminology used to define these complications. ${ }^{16}$ Gestational hypertension (i.e., hypertension during pregnancy or pregnancy-induced hypertension), by definition, occurs after 20 weeks of gestation. Preeclamptic/eclamptic hypertensive complications can start after 20 weeks of gestation but usually occur in late pregnancy. Fetal loss and growth restriction terminology is summarized in table $2 .{ }^{16}$ Understanding this terminology is essential to critically assessing the literature and being able to compare fetal outcome studies. 
Table 1. Hypertensive complications of pregnancy. ${ }^{16}$

\begin{tabular}{ll}
\hline Term & Definition \\
\hline Gestational hypertension & Blood pressure $\geq 140 / 90 \mathrm{mmHg}$ first time during pregnancy \\
& Blood pressure returns to normal 12 weeks postpartum \\
Preeclampsia & Minimum criteria \\
& Blood pressure $\geq 140 / 90 \mathrm{mmHg}$ after 20 weeks of gestation \\
& Proteinuria $\geq 300 \mathrm{mg} / 24$ hours or +1 dipstick \\
& Increased certainty of preeclampsia \\
Blood pressure $\geq 160 / 110 \mathrm{mmHg}$ & Proteinuria $2.0 \mathrm{~g} / 24$ hours or +2 dipstick \\
Serum creatinine $>1.2 \mathrm{mg} / \mathrm{dl}$ (new onset) \\
Platelets $<100,000 / \mathrm{mm}^{3}$ \\
Microangiopathic hemolysis (increased LDH) \\
Elevated ALT or AST \\
Persistent headaches or other cerebral or visual disturbance \\
Persistent epigastric pain
\end{tabular}

HELLP syndrome (old terminology)

Eclampsia

Superimposed preeclampsia (on chronic hypertension)

Chronic hypertension
Hemolysis, Elevated Liver functions, Low $\underline{\text { Platelets }}$

Preeclampsia plus seizures

New onset proteinuria $\geq 300 \mathrm{mg} / 24$ hours in hypertensive women but no proteinuria before 20 weeks of gestation

Sudden increase in proteinuria or blood pressure or platelet count $<100,000 / \mathrm{mm}^{3}$ in women with hypertension and proteinuria before 20 weeks of gestation

Blood pressure $\geq 140 / 90 \mathrm{mmHg}$ before pregnancy or diagnosed before 20 weeks of gestation not attributable to gestational trophoblastic disease

Or

Hypertension first diagnosed after 20 weeks of gestation and persistent after 12 weeks postpartum

ALT, alanine aminotransferase; AST, aspartate aminotransferase; LDH, lactate dehydrogenase.

\section{Lupus and Hypertensive Pregnancy Complications}

It is a diagnostic challenge to differentiate lupus disease manifestations from normal pregnancy-related effects or pregnancy-related hypertensive complications. At times, even the most experienced clinician cannot differentiate these with certainty and ends up treating both. Preeclampsia and eclampsia can mimic lupus with both presenting as edema, thrombocytopenia, hyperuricemia, anemia, hypertension, proteinuria, renal impairment, hematuria and additionally seizures in eclampsia. Furthermore, as detailed above, normal pregnancies can be accompanied by arthralgias, malar flush, thrombocytopenia and edema, which are similar to the symptoms of active lupus and complicate the treatment decision-making process. When a pregnant patient with lupus presents with hypertensive complications, the physician must determine if the clinical signs and symptoms are due to lupus or to pregnancy-related hypertension in order to proceed with appropriate testing and treatment. Active lupus is highly likely if clinical manifestations are present, such as malar rash with raised or scaly areas (i.e., rather than just malar redness), warm and swollen painful joints suggesting inflammation (i.e., rather than non-inflamed, achy joints), thrombocytopenia associated with antiplatelet antibodies, edema accompanied by nephrotic range proteinuria and low serum albumin, and red blood cell casts in urine specimens showing hematuria. However, at times, it may still be difficult to distinguish with certainty if the patient is exhibiting a normal pregnancy manifestation, a hypertensive complication related to the pregnancy or a lupus flare. In those situations, there is the general tendency to overtreat (i.e., to initiate standard treatment for both active lupus and the hypertensive complication of pregnancy) to ensure the safety of the mother and fetus and have a successful pregnancy outcome.

Hypertensive complications in pregnant women with lupus have been well-studied. Hypertensive complications of pregnancy occur in approximately $10 \%$ to $20 \%$ of all pregnant women with lupus, ${ }^{17-20}$ especially in the setting of lupus nephritis. ${ }^{21}$ Although chronic hypertension occurs in $28 \%$ of pregnant women with lupus, hypertensive complications are similarly increased in mothers with and without a history of pre-pregnancy hypertension. $^{22}$ Occurrence of preeclampsia/eclampsia is increased in lupus, ${ }^{20-24}$ and preeclampsia/Hemolysis, Elevated Liver, Low Platelet (HELLP) syndrome (table 1) correlates with 
Table 2. Adverse pregnancy outcomes. ${ }^{16}$

Term

Spontaneous abortions or miscarriages

Recurrent aborter or recurrent miscarriages

Fetal loss

Intrauterine fetal demise (IUFD) or stillbirth

Fetal wastage

Neonatal death

Small for gestational age

Low birth weight

Very low birth weight

Preterm birth or prematurity

the presence of maternal antiphospholipid antibodies and thrombocytopenia. ${ }^{25-27}$ Hypertensive complications in lupus increase the risk for preterm birth, intrauterine growth retardation (IUGR) and fetal loss. ${ }^{28,29}$ In general, expectant mothers with lupus have a greater likelihood of developing hypertensive complications of pregnancy and of experiencing preterm birth.

\section{The Effect of Pregnancy on Lupus}

The effects of pregnancy on lupus are controversial, and the reports of lupus flares during pregnancy are conflicting. There are studies that show an increase in lupus flares during pregnancy, ${ }^{19,30,31}$ and others that show no increase in flares. ${ }^{32-34}$ Lupus can flare during any trimester, as well as in the postpartum period. The reason for such discordant study results most likely stems from different definitions of flare, difficulty differentiating flare from hypertensive complications of pregnancy, assessment of disease activity and use of prophylactic corticosteroids in some patients. Risk factors for post-gestational flares include a high pregestational Systemic Lupus Erythematosus Disease Activity Index, low serum albumin, elevated anti-double-stranded DNA antibody titers, proteinuria and use of prednisone and hydroxychloroquine during pregnancy. ${ }^{35}$ Most flares involve minor organ manifestations (e.g., musculoskeletal, cutaneous) and are easily treated with low dose corticosteroids. However, some centers report major organ manifestations with renal flares occurring in $43 \% .{ }^{30}$ One way of quantitating lupus disease activity and flare is the use of lupus disease activity indices. These lupus disease activity indices have been modified to assess lupus disease activity in pregnancy in an effort to help differentiate pregnancy complications from lupus flare. Such indices include the SLE- Pregnancy Disease Activity Index (SLEPDAI), the Lupus Activity Index in Pregnancy (LAI-P), and the modified Systemic Lupus Activity Measure (m-SLAM). All are valid and modify the descriptors to include

\section{Definition}

Pregnancy loss $<20$ weeks of gestation

$\geq 3$ spontaneous abortions

Pregnancy loss from 10 weeks of gestation and onwards

Fetal death occurring at $\geq 20$ weeks of gestation

Sum of spontaneous abortions and stillbirths

Infant born live but died up to 28 days after birth

Birth weight $<10^{\text {th }}$ percentile

Birth weight $<2500 \mathrm{~g}$

Birth weight $<1500 \mathrm{~g}$

Gestational age $<37$ weeks

manifestations of normal and abnormal pregnancies. ${ }^{36}$ Although maternal death is uncommon in pregnancies complicated by lupus, it can occur if active renal or central nervous system disease is present.

Unfortunately, there are only a few laboratory tests that can help differentiate lupus flare from pregnancy complications. Clinical evidence specific for lupus includes rising anti-double-stranded DNA antibodies, positive direct Coombs' test, presence of red blood cell casts in the urine and the presence of antiplatelet antibody with thrombocytopenia. Due to estrogen-induced hepatic synthesis of complements in pregnancy, maternal lupus flares can be present with normal complement levels. Thus, a single measurement of complement levels will not be helpful in distinguishing a lupus flare. However, falling serial complement levels, even if in the normal range, suggest a lupus flare during pregnancy. One complement split product, $\mathrm{Ba}$, has been shown to be increased during lupus flares in pregnancy. ${ }^{37}$ However, this test is not widely available to clinicians. Best outcomes and treatment decisions generally occur when the experienced rheumatologist and obstetrician cooperatively assess the entire clinical picture and laboratory results. Clinical experience is a very valuable and helpful tool for determining optimal treatment.

\section{The Effect of Lupus on Fetal Outcomes}

It is well known that the risk of adverse fetal outcomes is increased in pregnancies complicated by lupus. ${ }^{18,35,38-44}$ The frequencies of spontaneous abortions and stillbirths are increased in women with lupus, with the stillbirth rate nearly 5 times greater than for non-lupus pregnancies. ${ }^{20}$ Preterm births occur in approximately $20 \%$ of lupus pregnancies and are associated with hypertensive medication use, corticosteroid use at conception, severe flare during pregnancy, nephrotic range proteinuria and anticardiolipin 
antibody. ${ }^{26,37,41,45-47}$ Fetal growth restriction occurs more frequently in pregnancies complicated by lupus and must be monitored closely. ${ }^{45}$ Adverse live birth outcomes correlate with lower pregestational serum albumin levels, elevated gestational anti-double-stranded DNA antibody titers and diabetes. 35

Fetal wastage may result from several factors, including disease activity, hypercoagulability and placental pathology. Renal impairment and hypercoagulability increase the risk for fetal wastage. ${ }^{45,48-55}$ Fetal growth is impaired when blood flow through the placenta is restricted by placental pathology. Hypercoagulability can result in placental infarctions and consequent fetal hypoxia. This hypercoagulability could be due to sticky platelet syndrome, ${ }^{56}$ pregnancy-induced protein $\mathrm{S}$ deficiency, increased inflammatory factors related to lupus disease activity (e.g., factor VIII, von Willebrand factor activity, von Willebrand factor antigen and fibrinogen), hyperhomocystinemia due to folate deficiency, (particularly in those who have gene polymorphisms for methylenetetrahydrofolate reductase) and antiphospholipid antibodies (e.g., lupus anticoagulant, anticardiolipin antibodies and false positive rapid plasma reagin test). Placental pathology in pregnancies complicated by lupus is characterized by ischemia/hypoxia, decidual vasculopathy, decidual and fetal thrombi, chronic villitis, decreased placental weight and placental infarctions along with deposits of fibrin, $\operatorname{IgG}, \operatorname{IgM}, \operatorname{IgA}$ and $\mathrm{C} 3$ in the trophoblastic membrane. ${ }^{57,58}$ Because fetal/placental blood flow is essential to fetal growth and survival, it is imperative to address this issue in caring for expectant patients with lupus.

Lupus nephritis can adversely affect fetal outcomes.45,48-53 Risk of obstetric complications and maternal mortality is increased if hypertension is present with lupus nephritis. Risk of fetal loss is markedly increased if lupus nephritis is active at conception, nephrotic range proteinuria is present serum creatinine is increased, hypertension is present or antiphospholipid antibodies are detected. $21,41,45,48-53,55$ There are conflicting reports regarding lupus nephritis flares during pregnancy, and it is unclear if pregnancy causes increased disease activity in patients with lupus nephritis. Lupus nephritis can appear for the first time during pregnancy, in the postpartum period or in the post-abortion period. Despite this, however, a history of lupus nephritis is not a contraindication to pregnancy, particularly if conception occurs when the nephritis has been quiescent for 6 months prior and can result in live-born infants under these circumstances. ${ }^{55,59}$ Although patients with lupus nephritis who have undergone renal transplant can maintain their pregnancies with live birth outcomes, the infants are typically preterm and have low birth weight. 55,60 Thus, women with lupus nephritis can have successful pregnancies under the right circumstances; however, they have a higher risk of losing the pregnancy and should be monitored very closely and counseled appropriately.
As mentioned previously, fetal growth restriction is a serious concern in pregnancies complicated by lupus ${ }^{44,61}$ and occurs more frequently in such pregnancies. Fetal growth restriction can occur even before the lupus is apparent in the mother which suggests a pre-disease state. ${ }^{45}$ The fetus seems to be a sensitive indicator of how sick the mother is. Risk factors for intrauterine growth restriction (IUGR) in lupus pregnancies include hypertension, active lupus (particularly lupus nephritis) and the presence of antiphospholipid antibodies. These pregnancies are usually monitored intensively by fetal ultrasound. The second trimester Doppler ultrasound examination may be useful as an indicator of IUGR and risk for pregnancy loss, ${ }^{62}$ and in particular, the last ultrasound within 5 weeks of delivery has been shown to best predict IUGR in lupus. ${ }^{63}$ When fetal growth restriction is detected in utero, delivery of the infant should be considered because the longer the fetus remains in an adverse environment, the more accentuated the growth restriction may become. The optimal time to deliver is determined by the maternal lupus status and the placental function. A positive risk to benefit ratio emerges as the pregnancy reaches 34 weeks of gestation, and neonatal survival after 34 weeks is similar to term infants in tertiary centers of developed countries. ${ }^{64}$

Neonatal lupus erythematosus (NLE) occurs via placental passage of maternal anti-Ro/SSA and anti-La/SSB antibodies which bind to fetal tissue and cause either congenital heart block (CHB) or noncardiac neonatal lupus. ${ }^{65}$ Although anti-Ro/SSA and anti-La/SSB antibodies have been determined to cause $\mathrm{CHB}$, they do not affect other pregnancy outcomes. ${ }^{66} \mathrm{NLE}$ presents with subacute cutaneous lupus, liver enzyme elevation and thrombocytopenia. ${ }^{65}$ NLE usually resolves approximately 6 to 8 months after birth when maternal antibodies disappear from fetal circulation.

$\mathrm{CHB}$ is rare and occurs in only $2 \%$ of infants born to mothers with anti-Ro/SSA and anti-La/SSB antibodies. ${ }^{67}$ The risk of $\mathrm{CHB}$ increases in infants born to mothers with a previous child having $\mathrm{CHB}$ and occurs in nearly $20 \%$ of pregnancies subsequent to the index pregnancy with CHB. ${ }^{65}$

CHB is irreversible and has significant mortality and morbidity ${ }^{71}$ with $>60 \%$ requiring permanent pacemakers and $10 \%$ developing severe cardiomyopathy. ${ }^{65} \mathrm{CHB}$ is caused by maternal anti-Ro/SSA and anti-La/SSB antibodies binding to cardiac tissue and causing a transient myocarditis and subsequent fibrosis of the atrioventricular node. During development of cardiac conduction tissue, there is a time limited expression of Ro/SSA and La/SSB antigens which become bound by maternal antibodies and induce inflammation of the tissue. ${ }^{65,68}$ Apoptosis has been documented to occur most extensively in regions containing conduction tissue in fetuses dying early, with IgG binding and ingestion by macrophages and transdifferentiation of cardiac fibroblasts to scarring myofibroblast phenotype. ${ }^{69}$ Passive transfer of maternal antibodies directed to a specific epitope of the Ro52 protein (i.e., anti-Ro/SSA antibodies) has been 
demonstrated to dysregulate calcium homeostasis and induce death of cultured cardiomyocytes. ${ }^{70}$ Autoantibody associated $\mathrm{CHB}$ has not been found to occur with major congenital anatomic defects and is usually identified in the late second trimester. ${ }^{71}$ It is recommended that anti-Ro/SSA and anti-La/SSB be checked in the first trimester and the first fetal echocardiogram (ECHO) be obtained at 16 weeks of gestation. ${ }^{65}$ If the PR interval of the fetal electrocardiogram (EKG) is $>150 \mathrm{~ms}$, as measured by pulsed-Doppler fetal ECHO or fetal electrocardiodiogram, ${ }^{72}$ or there are varying degrees of block, myocarditis or hydrops fetalis, then dexamethasone, which crosses the placenta at $4 \mathrm{mg}$ orally per day, is given for 6 weeks or longer. ${ }^{65}$ One approach suggested for severe hydrops fetalis is to remove circulating maternal antibodies by apheresis combined with dexamethasone treatment and delivery of the baby as soon as the lungs are deemed mature. ${ }^{65}$ Fetal ECHOs after 16 weeks of gestation may be monitored weekly for high risk infants (i.e., prior fetus with CHB/NLE) upon viability or every 2 weeks in lower risk settings. At birth, EKG should be performed along with a complete blood count, alkaline phosphatase test, and liver transaminases levels. Avoidance of sun exposure is also necessary for infants. An EKG should also be performed in any older sibling of an infant with CHB/NLE. ${ }^{65}$

\section{Immunosuppressive Medications During Pregnancy}

It is important to decide which immunosuppressive medications can be used during the pregnancies of women with lupus. The risk of maternal disease flare must be carefully weighed against risk of drug exposure to the fetus and induction of miscarriage. Despite the concern of prescribed medications and disease, the risk of minor physical anomalies is not increased in the offspring of mothers with lupus. ${ }^{73}$ In general, it is recommended that immunosuppressive medication required to control lupus disease be continued if possible, particularly if the patient has major organ involvement such as lupus nephritis. ${ }^{46}$ High activity lupus during pregnancy results in an increased frequency of preterm births and decreased frequency of live births, with nearly one-fourth of these pregnancies resulting in fetal loss. ${ }^{46}$ Table 3 summarizes the specifics related to use of immunosuppressive medications during pregnancy. Corticosteroids are relatively safe to use during pregnancy from a fetal standpoint, but they may contribute to maternal hypertension and gestational diabetes. Prednisolone is inactivated by the placenta, but dexamethasone crosses the placenta and enters the fetal circulation. Hence, when treating active lupus in the mother, prednisolone is used. However, when treating the infant in utero for $\mathrm{CHB}$, dexamethasone is used. Cytotoxics/antimetabolites and biologics, such as tumor necrosis factor-alpha antagonists, should be avoided if possible. Methotrexate (Rheumatrex, Trexall), leflunomide (Arava), cyclophosphamide (Cytoxan) and mycophenolate mofetil (CellCept) are contraindicated in pregnancy. Tumor necrosis factor-alpha antagonists (e.g., Remicade, Humira, Enbrel) are generally discontinued after the first missed period. Corticosteroids, azathioprine (Imuran, Azasan), cyclosporine (Neoral, Sandimmune, Gengraf), hydroxychloroquine
(Plaquenil), sulfasalazine (Azulfidine) and intravenous immunoglobulin may be used, if necessary, during pregnancy to control active maternal lupus disease.

\section{Suggested Guidelines}

All lupus pregnancies are considered high risk, and it is best if they can be cared for in a multidisciplinary setting with input from a maternal-fetal medicine specialist and a rheumatologist. The prenatal care of an expectant mother with lupus should involve assessment and treatment of three areas: hypertensive pregnancy complications, thrombophilia and lupus disease activity. Thus, many patients may also be followed by a nephrologist and coagulation specialist to assist with thrombophilia, hypertension management and renal function monitoring. Generally, fertility is not impaired in these women unless they have received cyclophosphamide chemotherapy as treatment, and thus, birth control should be addressed until the physician determines it is safe to become pregnant. ${ }^{74,75}$

The timing of conception is an important determinant in pregnancy outcome for lupus. We recommend that some preconceptual counseling be provided by the rheumatologist during the initial visits for all women of childbearing age, and a more formal preconceptual consultation with a maternal-fetal specialist is recommended when the patient expresses a desire to become pregnant. When the pregnancy is planned and if conception occurs when the disease has been in remission for 6 months prior, fetal and maternal outcomes are more favorable. ${ }^{17}$ If pregnancies occur when the lupus disease is active, if there is a history of major organ involvement (e.g., renal or central nervous system), or if there is renal impairment, they are more likely to result in poor fetal and maternal outcomes. ${ }^{18,38-44,48-53}$ Immunosuppressive medications should be minimized or discontinued, provided lupus disease activity is quiescent, to reduce exposure risk to the developing fetus particularly in the first trimester. However, if the patient requires immunosuppressive therapy for maintaining disease control, the woman should be kept on a regimen with the lowest risk to the fetus.

In our experience, having the rheumatologist see the expectant mother monthly to assess for lupus disease activity, hypertensive complications and fetal growth/complication monitoring optimizes treatments and outcomes. We have cared for many pregnant patients with lupus at our center and have developed a standard approach to monitor for disease activity, as well as fetal and maternal outcomes and potential complications. This approach provides a mechanism to address lupus disease activity, thrombophilia and fetal complications (table 4).

At our center, we use a protocol that we feel optimizes successful pregnancy outcomes, although there are other possible protocols used elsewhere. At the onset of pregnancy, the expectant mother has an initial set of laboratories and diagnostic tests to assess disease activity and maternal cardiopulmonary status (table 4). Many of our patients have 


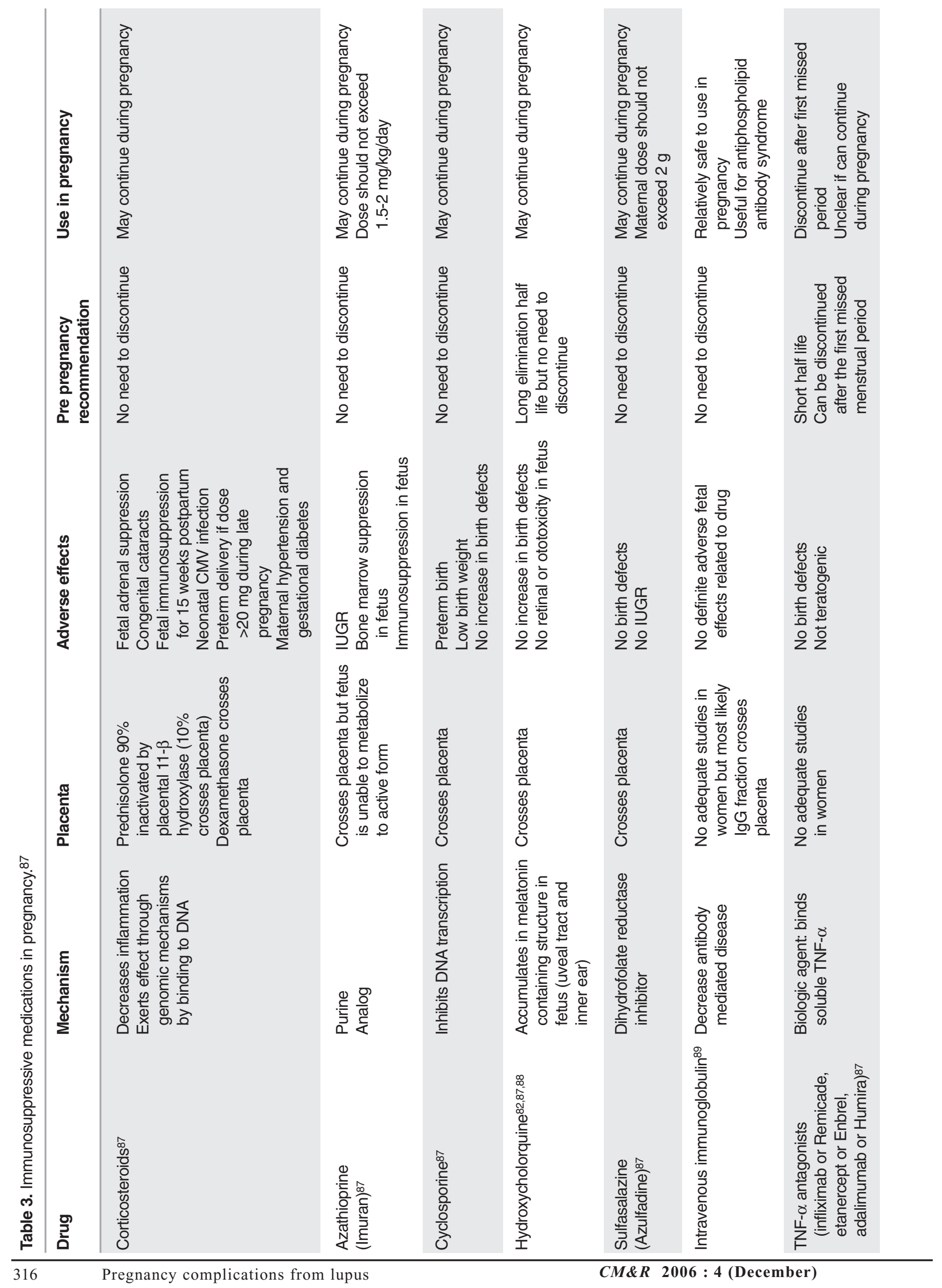




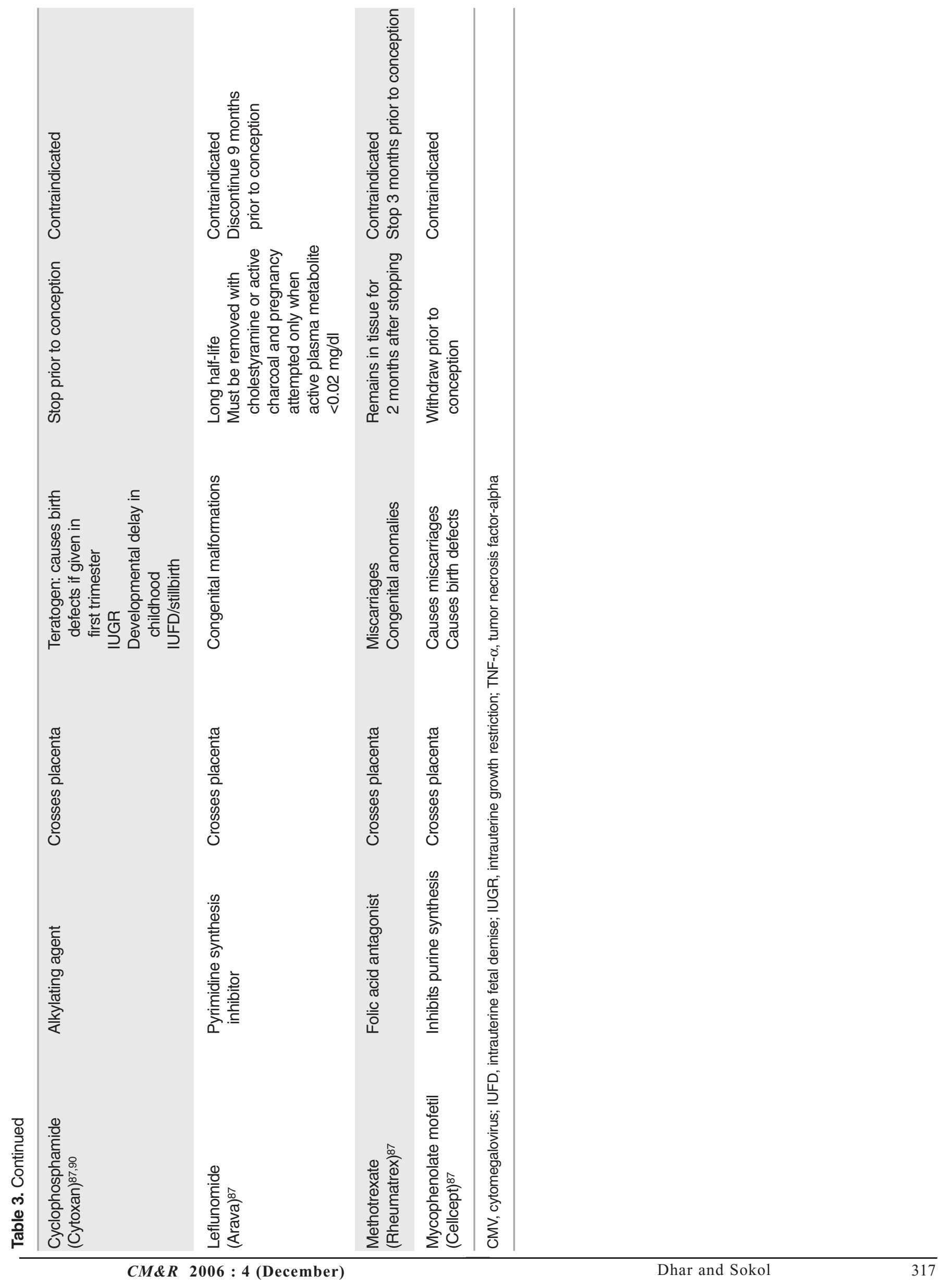


Table 4. Monitoring guideline for pregnancies complicated by lupus

\begin{tabular}{|c|c|c|c|}
\hline Month & Labs & Maternal monitoring & Fetal monitoring \\
\hline First trimester & $\begin{array}{l}\text { CBC with differential and platelets, } \\
\text { BUN, creatinine, liver function tests, } \\
\text { glucose, albumin, urinalysis, urine } \\
\text { protein/ creatinine ratio, C3, C4, } \mathrm{CH}_{50} \text {, } \\
\text { anti-ds-DNA antibody, anti-cardiolipin } \\
\text { antibody, RPR, lupus anticoagulant, } \\
\text { anti-Ro,/SSA antibody, anti-La/SSB } \\
\text { antibody, protein S activity, extended } \\
\text { thrombophilia profile }\end{array}$ & $\begin{array}{l}\text { Chest x-ray (optional) } \\
\text { Pulmonary function testing (optional) } \\
\text { Echocardiogram (optional) } \\
\text { Lupus Disease Activity Index Assessment } \\
\text { Hypertension and renal monitoring }\end{array}$ & \\
\hline 16 weeks & & & First fetal ECHO \\
\hline Monthly visits & $\begin{array}{l}\text { CBC with differential and platelets, } \\
\text { BUN, creatinine, liver function tests, } \\
\text { glucose, albumin, urinalysis, urine } \\
\text { protein/ creatinine ratio, } \mathrm{C} 3, \mathrm{C} 4, \mathrm{CH}_{50} \text {, } \\
\text { anti-ds-DNA antibody, anti-cardiolipin } \\
\text { antibody, protein } \mathrm{S} \text { activity, select } \\
\text { coagulation tests }\end{array}$ & $\begin{array}{l}\text { Lupus disease activity assessment } \\
\text { Hypertension and renal monitoring }\end{array}$ & $\begin{array}{l}\text { Fetal ECHO every } \\
1-2 \text { weeks after } \\
16 \text { weeks }\end{array}$ \\
\hline
\end{tabular}

BUN, blood urea nitrogen; CBC, complete blood count; ds-DNA, double stranded deoxyribonucleic acid; RPR, rapid plasma reagin

subclinical cardiopulmonary disease so most of our pregnant lupus patients get a chest $\mathrm{x}$-ray, pulmonary function test and cardiac ECHO during the first trimester, although this is not standard of care at other centers. We find these tests to be helpful for the identification and assessment of the status of interstitial lung disease, valvular heart disease and pulmonary hypertension, all of which can occasionally be clinically silent. To detect CHB as early as possible in mothers with anti-Ro/SSA and anti-La/SSB antibodies, studies in progress suggest that the first fetal ECHO be done at 16 weeks of gestation and then every 1 to 2 weeks depending on the findings. Although use of x-rays during pregnancy should be avoided, radiography that doesn't involve high doses of radiation to the abdominal or pelvic areas is not associated with any significant adverse events. ${ }^{76}$

Although it is not established standard of care, a thrombophilia assessment is performed in the first trimester at our center and includes an extended thrombophilia profile: fibrinogen, sticky platelet assay for platelet hyperfunction assessment, factor VIII activity, factor VII activity, homocystine, factor II, thrombin, von Willebrand factor activity and antigen, protein $\mathrm{S}$ activity, protein $\mathrm{C}$ activity, rapid plasma reagin test, anti-cardiolipin antibody and lupus anticoagulant. We feel this thrombophilia assessment optimizes the identification of hypercoagulability and required treatment. ${ }^{56,77,78}$ Monthly visits include clinical assessment of maternal lupus disease activity, monitoring for hypertensive complications of pregnancy and laboratory tests (table 4). When platelet hyperfunction is identified, we prescribe one baby aspirin daily, which should be continued until delivery to prevent thrombosis. If anticoagulation with heparin or low molecular weight heparin is required based on coagulation test results, anticoagulation should be discontinued just prior to delivery to avoid peripartum bleeding complications. ${ }^{78,79}$ Neither unfractionated heparin nor low molecular weight heparin cross the placenta; therefore, they are safe for the fetus. ${ }^{78,79}$ Flares should generally be treated with corticosteroids, and cytotoxics should be avoided. Strict control of blood pressure is essential throughout the pregnancy to optimize fetal growth. Delivery date and mode of delivery is guided by the health status of the mother and fetus. Generally, delivery after 32 weeks of gestation is desired, and the mode of delivery that will result in the least trauma to the mother and fetus is advised, particularly if anticoagulation is required or the infant has CHB or fetal distress.

Postpartum management of maternal disease is important, particularly since lupus can flare during this time and coagulation abnormalities may not immediately return to normal. If anticoagulation has been required during pregnancy, we continue this treatment for 3 months postpartum or until the abnormalities identified normalize. Patients should be slowly weaned off corticosteroids provided there is no disease activity. Immunosuppressive medications should be started postpartum if the patient experiences a lupus disease flare.

In general, it is best not to breast feed to avoid neonatal exposure to maternal drugs secreted in breast milk. Nonsteroidal anti-inflammatory drugs appear in low levels in breast milk, but if the mother chooses to breast feed, she should do so immediately before a dose to minimize infant exposure to the drug. ${ }^{80}$ Prednisone is excreted in breast milk, and if the daily dose exceeds $20 \mathrm{mg}$, the interval before 
nursing should be 4 hours. ${ }^{81}$ Hydroxychloroquine is secreted in breast milk, but it is felt that the levels are not toxic to infants. ${ }^{82}$ Azathioprine appears in breast milk, and breast feeding is not recommended while taking this drug. ${ }^{81}$ However, others feel that the levels of Azathioprine excreted in breast milk are low, and infants have been nursed safely by mothers taking this drug. ${ }^{80}$ Cyclosporine is secreted in breast milk, but due to the carcinogenic risk, nursing is generally prohibited even though infants have been reported to have nursed safely by mothers taking cyclosporine. 80 Cyclophosphamide is also excreted in breast milk, and nursing is prohibited while taking this medication due to risk of neonatal leucopenia and potential long-term carcinogenesis. ${ }^{80,81}$ No information is available at this time on breast feeding while taking mycophenolate mofetil, but it is recommended not to nurse while on this drug. ${ }^{80}$

Postpartum recovery is generally slow for women with lupus, because the mother may have had side effects of corticosteroids (e.g., weight gain), disease effects and due to the increased physical and emotional demands of caring for an infant while having a chronic disease. It is recommended that a mother with lupus arrange for family members to help care for her and the infant for the first few months to ensure that the mother can rest, recover and engage in a regular exercise program.

Of primary concern, are the long-term effects on the infants of mothers with lupus. Follow-up of children born to women with lupus has shown an increase in learning disabilities and non-right-handedness in male offspring, as well as increased anxiety and depression. ${ }^{83,84}$ Clearly this needs to be studied further, and intervention programs need to be developed to help families cope with the issue of caring for their children when the mother has a chronic illness.

\section{Conclusion}

Advancing technology and better understanding of the maternal-fetal dyad in lupus have improved outcomes in lupus pregnancies over the last 40 years. ${ }^{85}$ However, hypertensive complications remain a significant problem. ${ }^{86}$ If planned properly when the disease is quiescent and monitored closely in a multidisciplinary setting, pregnancy outcomes can be favorable in women with lupus. In conclusion, pregnancy is no longer considered an absolute contraindication in lupus. Under the watchful eye of the maternal-fetal medicine specialist and rheumatologist, women with lupus can successfully have children and fulfill their maternal desire.

\section{References}

1. Michet CJ Jr, McKenna CH, Elveback LR, Kaslow RA, Kurland LT. Epidemiology of systemic lupus erythematosus and other connective tissue diseases in Rochester, Minnesota, 1950 through 1979. Mayo Clin Proc 1985;60:105-113.

2. Hochberg MC. The incidence of systemic lupus erythematosus in Baltimore, Maryland, 1970-1977. Arthritis Rheum 1985;28:80-86.
3. Ward MM, Studenski S. Clinical manifestations of systemic lupus erythematosus. Identification of racial and socioeconomic influences. Arch Intern Med 1990;150:849-853.

4. Hochberg MC, Boyd RE, Ahearn JM, Arnett FC, Bias WB, Provost TT, Stevens MB. Systemic lupus erythematosus: a review of clinico-laboratory features and immunogenetic markers in 150 patients with emphasis on demographic subsets. Medicine (Baltimore) 1985;64:285-295.

5. Alarcon GS, McGwin G Jr, Bastian HM, Roseman J, Lisse J, Fessler BJ, Friedman AW, Reveille JD. Systemic lupus erythematosus in three ethnic groups. VII [correction of VIII]. Predictors of early mortality in the LUMINA cohort. LUMINA Study Group. Arthritis Rheum 2001;45:191-202.

6. Kaslow RA. High rate of death caused by systemic lupus erythematosus among U. S. residents of Asian descent. Arthritis Rheum 1982;25:414-418.

7. Kaslow RA, Masi AT. Age, sex, and race effects on mortality from systemic lupus erythematosus in the United States. Arthritis Rheum 1978;21:473-479.

8. Gordon MF, Stolley PD, Schinnar R. Trends in recent systemic lupus erythematosus mortality rates. Arthritis Rheum 1981;24:762-769.

9. Tan EM, Cohen AS, Fries JF, Masi AT, McShane DJ, Rothfield NF, Schaller JG, Talal N, Winchester RJ. The 1982 revised criteria for the classification of systemic lupus erythematosus. Arthritis Rheum 1982;25:1271-1277.

10. O'Neill SG, Schrieber L. Immunotherapy of systemic lupus erythematosus. Autoimmun Rev 2005;4:395-402.

11. Branch DW. Physiologic adaptations of pregnancy. Am J Reprod Immunol 1992;28:120-122.

12. Kitzmiller JL, Stoneburner L, Yelenosky PF, Lucas WE. Serum complement in normal pregnancy and pre-eclampsia. Am J Obstet Gynecol 1973;117:312-315.

13. Baines MG, Millar KG, Mills P. Studies of complement levels in normal human pregnancy. Obstet Gynecol 1974;43:806-810.

14. Burrows RF, Kelton JG. Incidentally detected thrombocytopenia in healthy mothers and their infants. N Engl J Med 1988;319:142-145.

15. Toglia MR, Weg JG. Venous thromboembolism during pregnancy. N Engl J Med 1996;335:108-114.

16. Cunningham FG, Leveno KJ, Bloom SL, Whitridge Williams J. Williams Obstetrics, 22 ${ }^{\text {nd }}$ ed. New York, NY: McGraw-Hill, 2005.

17. Boumpas DT, Balow JE. Outcome criteria for lupus nephritis trials: a critical overview. Lupus 1998;7:622-629.

18. Carmona F, Font J, Cervera R, Munoz F, Cararach V, Balasch J. Obstetrical outcome of pregnancy in patients with systemic Lupus erythematosus. A study of 60 cases. Eur J Obstet Gynecol Reprod Biol 1999;83:137-142.

19. Wong KL, Chan FY, Lee CP. Outcome of pregnancy in patients with systemic lupus erythematosus. A prospective study. Arch Intern Med 1991;151:269-273.

20. Dhar JP, Essenmacher LM, Ager JW, Sokol RJ. Pregnancy outcomes before and after a diagnosis of systemic lupus erythematosus. Am J Obstet Gynecol 2005;193:1444-1455.

21. Rahman FZ, Rahman J, Al-Suleiman SA, Rahman MS. Pregnancy outcome in lupus nephropathy. Arch Gynecol Obstet 2005;271:222-226.

22. Egerman RS, Ramsey RD, Kao LW, Bringman JJ, Bush AJ, Wan JY. Hypertensive disease in pregnancies complicated by systemic lupus erythematosus. Am J Obstet Gynecol 2005;193:1676-1679.

23. Wolfberg AJ, Lee-Parritz A, Peller AJ, Lieberman ES. Association of rheumatologic disease with preeclampsia. Obstet Gynecol 2004;103:1190-1193.

24. Yasmeen S, Wilkins EE, Field NT, Sheikh RA, Gilbert WM. Pregnancy outcomes in women with systemic lupus erythematosus. J Matern Fetal Med 2001;10:91-96. 
25. Le Thi Thuong D, Tieulie N, Costedoat N, Andreu MR, Wechsler B, Vauthier-Brouzes D, Aumaitre O, Piette JC. The HELLP syndrome in the antiphospholipid syndrome: retrospective study of 16 cases in 15 women. Ann Rheum Dis 2005;64:273-278.

26. Branch DW, Andres R, Digre KB, Rote NS, Scott JR. The association of antiphospholipid antibodies with severe preeclampsia. Obstet Gynecol 1989;73:541-545.

27. Chakravarty EF, Colon I, Langen ES, Nix DA, El-Sayed YY, Genovese MC, Druzin ML. Factors that predict prematurity and preeclampsia in pregnancies that are complicated by systemic lupus erythematosus. Am J Obstet Gynecol 2005;192:1897-1904.

28. Petri M. Hopkins Lupus Pregnancy Center: 1987 to 1996. Rheum Dis Clin North Am 1997;23:1-13.

29. Rahman P, Gladman DD, Urowitz MB. Clinical predictors of fetal outcome in systemic lupus erythematosus. J Rheumatol 1998;25:1526-1530.

30. Petri M, Howard D, Repke J. Frequency of lupus flare in pregnancy. The Hopkin's Lupus Pregnancy Center experience. Arthritis Rheum 1991;34:1538-1545.

31. Ruiz-Irastorza G, Lima F, Alves J, Khamashta MA, Simpson J, Hughes GR, Buchanan NM. Increased rate of lupus flare during pregnancy and the puerperium: a prospective study of 78 pregnancies. Br J Rheumatol 1996;35:133-138.

32. Lockshin MD, Reinitz E, Druzin ML, Murrman M, Estes D. Lupus pregnancy. Case-control prospective study demonstrating absence of lupus exacerbation during or after pregnancy. Am J Med 1984;77:893-898

33. Mintz G, Niz J, Gutierrez G, Garcia-Alonso A, Karchmer S. Prospective study of pregnancy in systemic lupus erythematosus. Results of a multidisciplinary approach. J Rheumatol 1986;13:732-739.

34. Urowitz MB, Gladman DD, Farewell VT, Stewart J, McDonald J. Lupus and pregnancy studies. Arthritis Rheum 1993;36:1392-1397.

35. Molad Y, Borkowski T, Monselise A, Ben-Haroush A, Sulkes J, Hod M, Feldberg D, Bar J. Maternal and fetal outcome of lupus pregnancy: a prospective study of 29 pregnancies. Lupus 2005; 14:145-151.

36. Buyon JP, Kalunian KC, Ramsey-Goldman R, Petri MA, Lockshin MD, Ruiz-Irastorza G, Khamashta M. Assessing disease activity in SLE patients during pregnancy. Lupus 1999;8:677-684.

37. Abramson SB, Buyon JP. Activation of the complement pathway: comparison of normal pregnancy, preeclampsia, and systemic lupus erythematosus during pregnancy. Am J Reprod Immunol 1992;28:183-187.

38. De Bandt M, Palazzo E, Belmatoug N, M'Bappe P, Hayem G, Kahn MF, Meyer O. Outcome of pregnancies in lupus: experience at one center. Ann Med Interne (Paris) 2000;151:87-92.

39. Rubbert A, Pirner K, Wildt L, Kalden JR, Manger B. Pregnancy course and complications in patients with systemic lupus erythematosus. Am J Reprod Immunol 1992;28:205-207.

40. Rahman P, Gladman DD, Urowitz MB. Clinical predictors of fetal outcome in systemic lupus erythematosus. J Rheumatol 1998;25:1526-1530.

41. Petri M. Pregnancy in SLE. Baillieres Clin Rheumatol 1998;12:449-476.

42. Tincani A, Faden D, Tarantini M, Lojacono A, Tanzi P, Gastaldi A, Di Mario C, Spatola L, Cattaneo R, Balestrieri G. Systemic lupus erythematosus and pregnancy: a prospective study. Clin Exp Rheumatol 1992;10:439-446.

43. Tozman EC, Urowitz MB, Gladman DD. Systemic lupus erythematosus and pregnancy. J Rheumatol 1980;7:624-632.
44. Julkunen H, Jouhikainen T, Kaaja R, Leirisalo-Repo M, Stephansson E, Palosuo T, Teramo K, Friman C. Fetal outcome in lupus pregnancy: a retrospective case-control study of 242 pregnancies in 112 patients. Lupus 1993;2:125-131.

45. Hayslett JP. Maternal and fetal complications in pregnant women with systemic lupus erythematosus. Am J Kidney Dis 1991; 17:123-126.

46. Clowse ME, Magder LS, Witter F, Petri M. The impact of increased lupus activity on obstetric outcomes. Arthritis Rheum 2005;52:514-521

47. Clark CA, Spitzer KA, Nadler JN, Laskin CA. Preterm deliveries in women with systemic lupus erythematosus. J Rheumatol 2003;30:2127-2132.

48. Le Thi Huong D, Wechsler B, Godeau P. Epidemiologic study of pregnancy complicated by lupus. Ann Med Interne (Paris) 1990;141:239-243.

49. Bobrie G, Liote F, Houillier P, Grunfeld JP, Jungers P. Pregnancy in lupus nephritis and related disorders. Am J Kidney Dis 1987;9:339-343.

50. Burkett G. Lupus nephropathy and pregnancy. Clin Obstet Gynecol 1985;28:310-323.

51. Hayslett JP. Effect of pregnancy in patients with SLE. Am J Kidney Dis 1982;2:223-228.

52. Jungers P, Dougados M, Pelissier C, Kuttenn F, Tron F, Lesavre P, Bach JF. Problems posed by pregnancy in women with lupus nephropathy. Presse Med 1983;12:345-349.

53. Cortes-Hernandez J, Ordi-Ros J, Paredes F, Casellas M, Castillo F, Vilardell-Tarres M. Clinical predictors of fetal and maternal outcome in systemic lupus erythematosus: a prospective study of 103 pregnancies. Rheumatology (Oxford) 2002;41:643-650.

54. Ramsey-Goldman R, Kutzer JE, Kuller LH, Guzick D, Carpenter AB, Medsger TA Jr. Pregnancy outcome and anti-cardiolipin antibody in women with systemic lupus erythematosus. Am J Epidemiol 1993;138:1057-1069.

55. Germain S, Nelson-Piercy C. Lupus nephritis and renal disease in pregnancy. Lupus 2006;15:148-155.

56. Andersen JC, Dhar P, Essenmacher L, Ager J, Sokol R. Determinants of thrombophilia in an urban systemic lupus erythematosus population. Blood 2005;106 [abstract 4134].

57. Magid MS, Kaplan C, Sammaritano LR, Peterson M, Druzin ML, Lockshin MD. Placental pathology in systemic lupus erythematosus: a prospective study. Am J Obstet Gynecol 1998;179:226-234.

58. Ogishima D, Matsumoto T, Nakamura Y, Yoshida K, Kuwabara Y. Placental pathology in systemic lupus erythematosus with antiphospholipid antibodies. Pathol Int 2000;50:224-229.

59. Moroni G, Ponticelli C. The risk of pregnancy in patients with lupus nephritis. J Nephrol 2003;16:161-167.

60. McGrory CH, McCloskey LJ, DeHoratius RJ, Dunn SR, Moritz MJ, Armenti VT. Pregnancy outcomes in female renal recipients: a comparison of systemic lupus erythematosus with other diagnoses. Am J Transplant 2003;3:35-42.

61. Nossent HC, Swaak TJ. Systemic lupus erythematosus. VI. Analysis of the interrelationship with pregnancy. J Rheumatol 1990;17:771-776.

62. Le Thi Huong D, Wechsler B, Vauthier-Brouzes D, Duhaut P, Costedoat N, Andreu MR, Lefebvre G, Piette JC. The second trimester Doppler ultrasound examination is the best predictor of late pregnancy outcome in systemic lupus erythematosus and/or the antiphospholipid syndrome. Rheumatology (Oxford) 2006;45:332-338.

63. Witter FR, Petri M. Antenatal detection of intrauterine growth restriction in patients with systemic lupus erythematosus. Int J Gynaecol Obstet 2000;71:67-68.

64. Logghe H, Walker JJ. Towards improved neonatal outcome: future strategies. Semin Fetal Neonatal Med 2004;9:491-498. 
65. Buyon JP, Clancy RM. Neonatal lupus: review of proposed pathogenesis and clinical data from the US-based Research Registry for Neonatal Lupus. Autoimmunity 2003;36:41-50.

66. Brucato A, Doria A, Frassi M, Castellino G, Franceschini F, Faden D, Pisoni MP, Solerte L, Muscara M, Lojacono A, Motta M, Cavazzana I, Ghirardello A, Vescovi F, Tombini V, Cimaz R, Gambari PF, Meroni PL, Canesi B, Tincani A. Pregnancy outcome in 100 women with autoimmune diseases and anti-Ro/SSA antibodies: a prospective controlled study. Lupus 2002;11:716-721.

67. Brucato A, Frassi M, Franceschini F, Cimaz R, Faden D, Pisoni MP, Muscara M, Vignati G, Stramba-Badiale M, Catelli L, Lojacono A, Cavazzana I, Ghirardello A, Vescovi F, Gambari PF, Doria A, Meroni PL, Tincani A. Risk of congenital complete heart block in newborns of mothers with anti-Ro/SSA antibodies detected by counterimmunoelectrophoresis: a prospective study of 100 women. Arthritis Rheum 2001;44:1832-1835.

68. Buyon JP, Clancy RM. Neonatal lupus: basic research and clinical perspectives. Rheum Dis Clin North Am 2005;31:299-313, vii.

69. Clancy RM, Kapur RP, Molad Y, Askanase AD, Buyon JP. Immunohistologic evidence supports apoptosis, IgG deposition, and novel macrophage/fibroblast crosstalk in the pathologic cascade leading to congenital heart block. Arthritis Rheum 2004;50:173-182.

70. Salomonsson S, Sonesson SE, Ottosson L, Muhallab S, Olsson T, Sunnerhagen M, Kuchroo VK, Thoren P, Herlenius E, Wahren-Herlenius M. Ro/SSA autoantibodies directly bind cardiomyocytes, disturb calcium homeostasis, and mediate congenital heart block. J Exp Med 2005;201:11-17.

71. Buyon JP, Hiebert R, Copel J, Craft J, Friedman D, Katholi M, Lee LA, Provost TT, Reichlin M, Rider L, Rupel A, Saleeb S, Weston WL, Skovron ML. Autoimmune-associated congenital heart block: demographics, mortality, morbidity and recurrence rates obtained from a national neonatal lupus registry. J Am Coll Cardiol 1998;31:1658-1666.

72. Sokol RJ, Hutchison P, Krouskop RW, Brown EG, Reed G, Vasquez H. Congenital complete heart block diagnosed during intrauterine fetal monitoring. Am J Obstet Gynecol 1974; 120:1115-1117.

73. Bonaminio PN, de Regnier R, Chang E, Day N, Manzi S, Ramsey-Goldman R. Minor physical anomalies are not increased in the offspring of mothers with systemic lupus erythematosus. Ann Rheum Dis 2006;65:246-248.

74. Ostensen M. New insights into sexual functioning and fertility in rheumatic diseases. Best Pract Res Clin Rheumatol 2004;18:219-232.

75. Gordon C. Pregnancy and autoimmune diseases. Best Pract Res Clin Rheumatol 2004;18:359-379.

76. Lowe SA. Diagnostic radiography in pregnancy: risks and reality. Aust N Z J Obstet Gynaecol 2004;44:191-196.

77. Andersen JC, Sagar H, Syed M, Hagood AS, Dhar P. Prothrombotic change in inflammation-inducible coagulation factors identifies thrombotic risk in SLE patients with antiphospholipid antibodies. Blood 2003;102 [abstract 4188].

78. Ruiz-Irastorza G, Khamashta MA, Hughes GR. Systemic lupus erythematosus and antiphospholipid syndrome during pregnancy: maternal and fetal complications and their management. Isr Med Assoc J 2000;2:462-469.

79. Ruiz-Irastorza G, Khamashta MA. Management of thrombosis in antiphospholipid syndrome and systemic lupus erythematosus in pregnancy. Ann N Y Acad Sci 2005;1051:606-612.
80. Ostensen M, Khamashta M, Lockshin M, Parke A, Brucato A, Carp H, Doria A, Rai R, Meroni P, Cetin I, Derksen R, Branch W, Motta M, Gordon C, Ruiz-Irastorza G, Spinillo A, Friedman D, Cimaz R, Czeizel A, Piette JC, Cervera R, Levy RA, Clementi M, De Carolis S, Petri M, Shoenfeld Y, Faden D, Valesini G, Tincani A. Anti-inflammatory and immunosuppressive drugs and reproduction. Arthritis Res Ther 2006;8:209.

81. Petri M. Immunosuppressive drug use in pregnancy. Autoimmunity 2003;36:51-56.

82. Costedoat-Chalumeau N, Amoura Z, Huong DL, Lechat $P$, Piette JC. Safety of hydroxychloroquine in pregnant patients with connective tissue diseases. Review of the literature. Autoimmun Rev 2005;4:111-115.

83. Ross G, Sammaritano L, Nass R, Lockshin M. Effects of mothers' autoimmune disease during pregnancy on learning disabilities and hand preference in their children. Arch Pediatr Adolesc Med 2003;157:397-402.

84. Neri F, Chimini L, Bonomi F, Filippini E, Motta M, Faden D, Lojacono A, Rebaioli CB, Frassi M, Danieli E, Tincani A. Neuropsychological development of children born to patients with systemic lupus erythematosus. Lupus 2004;13:805-811.

85. Clark CA, Spitzer KA, Laskin CA. Decrease in pregnancy loss rates in patients with systemic lupus erythematosus over a 40-year period. J Rheumatol 2005;32:1709-1712.

86. Chakravarty EF, Nelson L, Krishnan E. Obstetric hospitalizations in the United States for women with systemic lupus erythematosus and rheumatoid arthritis. Arthritis Rheum 2006;54:899-907.

87. Ostensen M. Disease specific problems related to drug therapy in pregnancy. Lupus 2004;13:746-750.

88. Borba EF, Turrini-Filho JR, Kuruma KA, Bertola C, Pedalini ME, Lorenzi MC, Bonfa E. Chloroquine gestational use in systemic lupus erythematosus: assessing the risk of child ototoxicity by pure tone audiometry. Lupus 2004;13:223-227.

89. Gordon C, Kilby MD. Use of intravenous immunoglobulin therapy in pregnancy in systemic lupus erythematosus and antiphospholipid antibody syndrome. Lupus 1998;7:429-433.

90. Clowse ME, Magder L, Petri M. Cyclophosphamide for lupus during pregnancy. Lupus 2005;14:593-597.

\section{Author Affiliations}

Josephine Patricia Dhar, MD

Assistant Professor of Medicine

Internal Medicine/Rheumatology

Wayne State University School of Medicine

Detroit, Michigan USA

Robert J Sokol, MD

Director, C.S. Mott Center for Human Growth and Development Distinguished Professor of Obstetrics and Gynecology

Wayne State University School of Medicine

Detroit, Michigan USA 